\title{
REMOTELY OPERATED VEHICLE (ROV) UNTUK EKSPLORASI BAWAH AIR DI LINGKUNGAN INDUSTRI PERKAPALAN
}

\author{
R. A. Septian ${ }^{1}$, A. Rahmania ${ }^{2}$, M. I. Nugraha ${ }^{3}$, Yudhi $^{4}$ \\ 1,2,3,4 Jurusan Teknik Elektro dan Informatika - Politeknik Manufaktur Negeri Bangka Belitung \\ Kawasan Industri Air Kantung, Sungailiat-Bangka, 33211 \\ Tel: 0717-93586, Fax: 0717-93585, rahmat.andi.1994@gmail.com
}

\begin{abstract}
Remotely Operated Vehicle (ROV) is one of the robots that are being developed in Indonesia for exploring underwater potential. In this final project, the ROV was designed and controlled by Arduino for diving underwater with maximum depth of 30 meters. The application of ROV is that to take pictures and record video of underwater environment in real time by using camera monitored through a $P C$. The construction and the electronics device of the ROV were made waterproof. The actuator used was bilge pump motor $1100 \mathrm{GPH} 12$ Volt as thruster motor. The thruster driver used was a two channel-relay and the vision system of robot was a CCD camera. Based on the results, it was obtained that the ROV was able to move according to the commands provided by operator using a remote control. At three meters depth, the robot can move forward with average speed of $0.161 \mathrm{~m} / \mathrm{s}$. For up and down movement at 3 meters depth, the robot can go up with average speed of $0.09 \mathrm{~m} / \mathrm{s}$ and down with average speed of 0.17 $\mathrm{m} / \mathrm{s}$. From the data, it can be concluded that the ROV can maneuver and use the camera properly.
\end{abstract}

Keywords: ROV, Arduino, Thruster, CCD camera.

\begin{abstract}
Abstrak
Remotely Operated Vehicle (ROV) merupakan salah satu robot tanpa awak yang sedang dikembangkan di Indonesia untuk mengeksplorasi potensi bawah air. Pada Proyek Akhir ini, sebuah ROV dirancang dan dibuat dengan kontrol berbasis Arduino yang dapat menyelam di bawah air pada kedalaman mencapai 30 meter. Aplikasi ROV ini adalah untuk mengambil gambar dan merekam video lingkungan dibawah air secara real time melalui kamera yang dipantau melalui PC dengan menggunakan media transmisi berupa kabel. Konstruksi dan perangkat elektronik ROV dibuat kedap air dengan aktuator yang digunakan berupa motor bilge pump 1100GPH 12 volt sebagai motor thruster. Driver thruster yang digunakan berupa relay 2 channel dan sistem vision robot menggunakan kamera CCD sebagai pengambil gambar di bawah air. Berdasarkan hasil yang didapat, ROV dapat bergerak sesuai dengan perintah yang diberikan oleh operator dengan menggunakan remote atau joystick. Pada kedalaman 3 meter, robot dapat bergerak maju dengan kecepatan rata-rata $0,161 \mathrm{~m} / \mathrm{s}$. Untuk pergerakan naik turun pada kedalaman 3 meter, robot dapat naik dengan kecepatan rata-rata $0,09 \mathrm{~m} / \mathrm{s}$ dan turun dengan kecepatan rata-rata 0,17 m/s. Dari data tersebut maka dapat disimpulkan bahwa ROV yang sudah dibuat dapat bermanuver dan mengambil gambar serta video di bawah air.
\end{abstract}

Kata kunci: ROV, Arduino, Thruster, CCD kamera.

\section{PENDAHULUAN}

Dalam dunia industri perkapalan, khususnya di Bangka Belitung, PT. DAK merupakan salah satu shipyard yang terbesar. Dalam pekerjaan perbaikan atau perawatan kapal, pada umumnya aktivitas tersebut bersifat dry dock atau dilakukan diatas air. Hal ini dikarenakan terbatasnya olah gerak dan penglihatan yang bisa dilakukan di dalam air, sehingga identifikasi kerusakan peralatan kapal yang berada dibawah garis air akan memakan waktu yang lama dan efektivitas produksi berkurang yang pastinya akan menyebabkan cost yang timbul akan besar juga. Oleh karena itu ROV dibutuhkan untuk kebutuhan penjelajahan bawah air saat perbaikan ataupun prediktif maintenance body kapal dan diharapkan dapat meningkatkan efektifitas produksi dan percepatan identifikasi kerusakan di bawah air. Salah satu robot yang pernah dikembangkan di Indonesia adalah robot tanpa awak yang dapat dioperasikan dengan menggunakan remote yang diberi nama Mini Remotely Operated Vehicle (ROV) buatan Pusat Pengkajian dan Perekayasaan Teknologi Kelautan dan Perikanan (P3TKP). Mini ROV yang 
dibuat oleh Pusat Pengkajian dan Perekayasaan Teknologi Kelautan dan Perikanan (P3TKP) digunakan untuk mengeksplorasi potensi bawah air yang biasanya masih dilakukan secara manual dengan menggunakan penyelaman tradisional. Kegiatan observasi bawah air akan terasa sangat sulit dan merepotkan jika proses penyelaman harus dilakukan berulang kali dikarenakan keterbatasan fisik manusia tersebut. Mini ROV ini dibuat untuk membantu manusia melakukan observasi bawah air dengan aman hingga kedalaman 200 meter[2]. ROV sudah pernah digunakan di Indonesia, salah satunya pada saat pencarian Pesawat Air Asia QZ8501. ROV tersebut digunakan untuk memastikan keberadaan pesawat sebelum tim penyelam diturunkan [3].

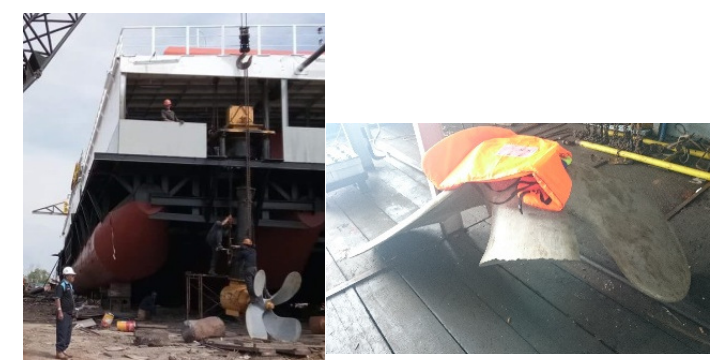

Gambar 1. Identifikasi rudder propeller di atas air

Gambar diatas merupakan contoh kasus pemeriksaan rudder propeller kapal yang patah, dimana pada awalnya hanya 1 blade yang patah, namun akibat keterlambatan pemeriksaan jadi keseluruhan blades ikut patah dan menimbulkan kerugian yang lebih besar terhadap perusahaan.

\section{LANDASAN TEORI}

\subsection{Pengertian dan sejarah ROV}

Definisi ROV menurut Marine Technology Society ROV Commitee's dalam "Operational Guideliner for ROV's (1984) dan The National Research Council Commitee's dalam “Undersea Vehicles and National Needs" (1996) merupakan sebuah robot bawah laut yang dikendalikan oleh operator untuk tetap dalam kondisi yang aman, saat ROV bekerja di lingkungan yang berbahaya [7].

\subsection{Gaya Apung / Bouyancy}

Gaya yang diberikan oleh fluida pada benda yang tenggelam didalamnya dinamakan gaya apung atau bouyancy. Gaya ini tergantung pada kerapatan fluida dan volume benda, tetapi tidak pada komposisi atau bentuk benda, dan besarnya sama dengan berat fluida yang dipindahkan oleh benda. Berdasarkan prinsip Archimedes menyatakan bahwa, "Sebuah benda yang tenggelam seluruhnya atau sebagian dalam suatu fluida diangkat ke atas oleh sebuah gaya yang sama dengan berat fluida yang dipindahkan", dengan persamaan sebagai berikut [4].

$$
\mathrm{Fa}=\rho_{\mathrm{f}} \times \mathrm{V}_{\mathrm{bf}} \times \mathrm{g}
$$

Keterangan :

$\mathrm{F}_{\mathrm{a}}$ : gaya apung $(\mathrm{N})$

$\mathrm{W}_{\mathrm{f}}$ : berat benda dalam zat cair / fluida (N)

$\mathrm{g}$ : percepatan gravitasi $\left(\mathrm{m} / \mathrm{s}^{2}\right)$

$\rho_{f}$ : massa jenis zat cair $\left(\mathrm{kg} / \mathrm{m}^{3}\right)$

$\mathrm{V}_{\mathrm{bf}}$ : volume benda yang tercelup dalam zat cair $\left(\mathrm{m}^{3}\right)$

\subsection{Tekanan dalam fluida}

Gaya per satuan luas yang diadakan oleh fluida sama di setiap titik pada permukaan benda. Gaya per satuan luas disebut dengan tekanan fluida $(\mathrm{P})$. Jika $\mathrm{P}_{0}$ adalah tekanan di bagian atas dan $\mathrm{P}$ adalah tekanan di dasar, maka gaya netto ke atas yang disebabkan oleh beda tekanan ini adalah PA $\mathrm{P}_{0} \mathrm{~A}$. Dengan membuat gaya ke atas netto ini sama dengan berat kolom, maka didapatkan :

$P A-P_{0} A=\rho . A . h . g$

atau

$P=P_{0}+\rho \cdot g \cdot h \quad$ ( $\rho$ konstan $)$ 
Keterangan :

$\mathrm{P}$ : tekanan di dasar $\left(\mathrm{N} / \mathrm{m}^{2}\right.$ atau $\mathrm{Pa}$ atau atm)

$\mathrm{P}_{0}$ : tekanan di permukaan air $\left(\mathrm{N} / \mathrm{m}^{2}\right.$ atau $\mathrm{Pa}$ atau atm)

$\rho:$ massa jenis zat cair $\left(\mathrm{kg} / \mathrm{m}^{3}\right)$

$\mathrm{g}:$ gravitasi $\left(\mathrm{m} /\right.$ detik $\left.^{2}\right)$

$\mathrm{h}$ : tinggi air atau kedalaman air (m)

\section{HASIL DAN PEMBAHASAN}

\subsection{Rancangan ROV}

Perancangan ROV dibagi menjadi 3 bagian yaitu perancangan konstruksi, perancangan hardware, dan perancangan software. Perancangan ROV tersebut mempertimbangkan beberapa faktor meliputi bentuk, bahan, dan komponen yang dapat mempengaruhi fleksibilitas dan kemampuan ROV dalam menyelam di bawah air serta didukung oleh software yang mampu membuat ROV bergerak dan mengambil gambar maupun video di bawah air.

Berikut merupakan gambar rancangan ROV yang dibuat :

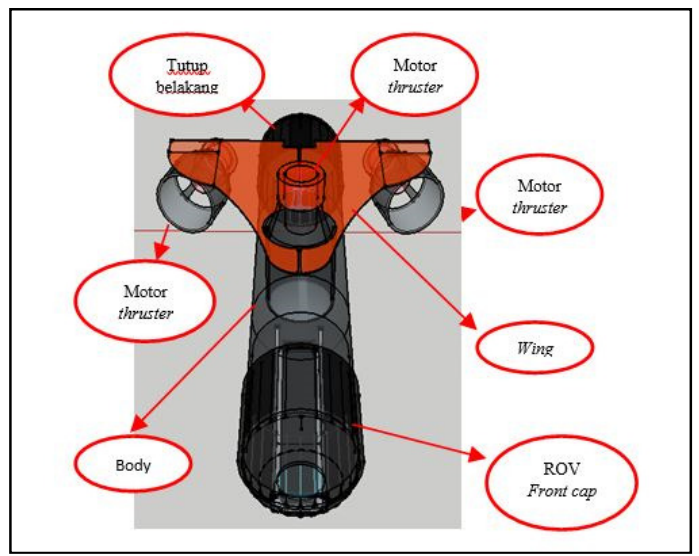

Gambar 2. Desain ROV

Material yang digunakan dalam pembuatan ROV adalah Plastic PVC yang direkatkan dengan epoxy glue serta bahan metal ( besi ) yang digunakan sebagai pemberat, adapun controller yang digunakan adalah arduino platform, sedangkan thruster yang digunakan berupa modifikasi 3 buah bilge pump dengan propeller type 5 blade.

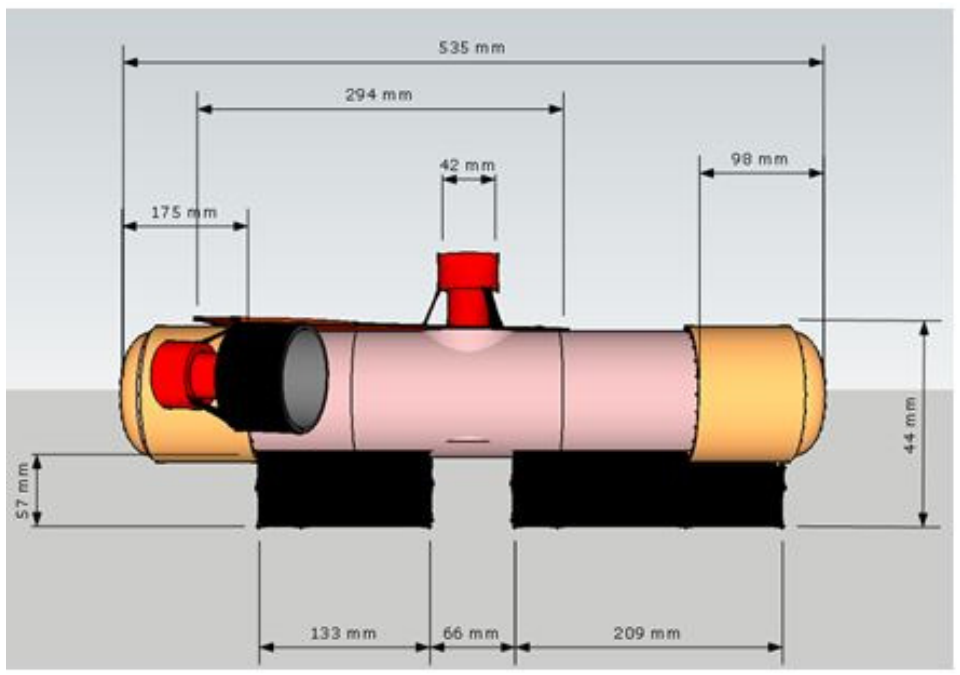

Gambar 3. Dimensi ROV 
ROV didesain kecil sehingga thruster yang digunakan akan cukup kuat untuk membuat ROV bermanuver dengan cepat di dalam air.

\subsection{Persamaan Tekanan Fluida}

Tekanan hidrostatik dipengaruhi oleh kedalaman, gravitasi, dan massa jenis zat cair (fluida). Untuk itu persamaan tekanan fluida dapat dirumuskan sebagai berikut [4]:

$P=P 0+\rho . g . h$

Pengaruh ROV terhadap tekanan di kolam pada kedalaman maksimal 3 meter berdasarkan perhitungan tekanan fluida di bawah permukaan air apabila tekanan di permukaan air adalah 1 atm adalah sebagai berikut :

Jika PO = 1 atm = 101,325 kPa, $\rho=103 \mathrm{~kg} / \mathrm{m3}$, dan $\mathrm{g}=9.81 \mathrm{~N} / \mathrm{kg}$, maka didapatkan nilai tekanan di kedalaman 3 meter berdasarkan persamaan (1) adalah sebagai berikut[4][5]:

$$
\begin{aligned}
P & =101,325 \mathrm{kPa}+(103 \mathrm{~kg} / \mathrm{m} 3) \cdot(9,81 \mathrm{~N} / \mathrm{kg}) \cdot(3 \mathrm{~m}) \\
& =101,325 \mathrm{kPa}+29,43 \mathrm{kPa} \\
& =130,755 \mathrm{kPa}=0,130755 \mathrm{~N} / \mathrm{m} 2(1 \mathrm{~Pa}=1 \mathrm{~N} / \mathrm{m} 2)
\end{aligned}
$$

Nilai kekuatan bahan pipa PVC tipe D > P (tekanan dalam air hingga 3 meter), sehingga dari perhitungan di atas dapat disimpulkan bahwa dengan menggunakan pipa PVC tipe D, maka pipa tersebut dapat menahan tekanan di kedalaman hingga 3 meter.

\subsection{Persamaan Daya Apung}

Besarnya gaya apung menurut prinsip Archimedes adalah sebagai berikut [4][5]:

$F a=\rho_{f} \times V_{R O V} \times g$

Untuk mendapatkan nilai daya apung yang dihasilkan ROV, maka perlu dilakukan perhitungan Volume total ROV $\left(\mathrm{V}_{\mathrm{ROV}}\right)$ tersebut. Adapun perhitungan $\mathrm{V}_{\mathrm{ROV}}$ terdiri dari beberapa bagian yaitu Volume badan ROV $\left(\mathrm{V}_{\mathrm{BR}}\right)$, Volume sayap ROV $\left(\mathrm{V}_{\mathrm{SR}}\right)$, Volume motor thruster $\left(\mathrm{V}_{\text {Tmotor }}\right)$, Volume pemberat $\left(\mathrm{V}_{\text {pemberat }}\right)$, dan Volume cover motor thruster ROV $\left(\mathrm{V}_{3 \text { cover } \mathrm{T}}\right)$. Dari hasil perhitungan tersebut, maka didapatlah total volume ROV ( $\mathrm{V}_{\mathrm{ROV}}$ ) yang dapat mempengaruhi daya apung yaitu [4][5]:

$$
\begin{aligned}
V_{R O V}= & V_{B R}+V_{S R}+V_{\text {Tmotor }}+V_{\text {pemberat }}+V_{3 \text { Covert }} . .(6) \\
= & 2.938 .843,75 \mathrm{~mm}^{3}+172.921,88 \mathrm{~mm}^{3}+ \\
& 497.493,75 \mathrm{~mm}^{3}+120.000 \mathrm{~mm}^{3}+70.650 \mathrm{~mm}^{3} \\
= & 3.799 .909,38 \mathrm{~mm}^{3} \\
V_{\text {ROV }}= & 0,003799909 \mathrm{~m}^{3} .
\end{aligned}
$$

Massa benda di udara $(\mathrm{m})$ adalah 5 kilogram, maka [4][5]:

massa jenis benda $\left(\rho_{b}\right)=\frac{m}{V}$

$$
\begin{aligned}
& =5 \mathrm{~kg} / 0,003799909 \mathrm{~m}^{3} \\
\rho_{\mathrm{b}} & =1.315,82 \mathrm{~kg} / \mathrm{m}^{3} .
\end{aligned}
$$

Massa jenis zat cair $\left(\rho_{\mathrm{f}}\right)=1.000 \mathrm{~kg} / \mathrm{m}^{3}$.

Massa jenis benda berdasarkan hasil perhitungan di atas adalah sebesar $1.315,82 \mathrm{~kg} / \mathrm{m}^{3}$. Sedangkan benda dapat dikatakan mengapung apabila $\rho_{\mathrm{b}}<\rho_{\mathrm{f}}[5]$.

Dari hasil perhitungan ini maka dapat disimpulkan bahwa $\rho_{b}>\rho_{f}$ dan mengakibatkan benda tenggelam. Berdasarkan persamaan (2), jika percepatan gravitasi $(\mathrm{g})=9,81 \mathrm{~m} / \mathrm{s}^{2}$, massa jenis zat cair $\left(\rho_{\mathrm{f}}\right)$ $=1000 \mathrm{~kg} / \mathrm{m}^{3}$, dan dengan Volume benda campuran $\left(\mathrm{V}_{\mathrm{ROV}}\right)=0,003799909 \mathrm{~m}^{3}$, maka gaya apung $(\mathrm{Fa})$ dan gaya berat benda $(\mathrm{W})$ adalah $[4,5]$ :

$$
\begin{aligned}
& >\mathrm{Fa}=\rho_{f} \times V_{R O V} \times g \\
& =1000 \mathrm{~kg} / \mathrm{m}^{3} \times 0,0037 \mathrm{~m}^{3} \times 9.81 \mathrm{~m} / \mathrm{s}^{2} \\
& =37,2771 \mathrm{~N}=37,2771 \mathrm{~kg} \cdot \mathrm{m} / \mathrm{s}^{2} \text {. } \\
& >\quad W=\text { massa } \times g \text {. } \\
& =5 \mathrm{~kg} \times 9,81 \mathrm{~m} / \mathrm{s}^{2} \\
& =49,05 \mathrm{~N} \text {. }
\end{aligned}
$$




\subsection{Konstruksi ROV}

Pembuatan ROV menggunakan bahan pipa PVC ukuran $\varnothing 100 \mathrm{~mm}$ sebagai badan ROV dan tempat peletakan komponen. Untuk merakit pipa PVC tersebut menggunakan lem epoxy sebagai perekat antara bagian satu dengan bagian lainnya. Untuk pemberatnya digunakan besi berukuran $80 \mathrm{x}$ $25 \times 20$ agar robot dapat melayang di dalam air.

Hasil konstruksi ROV dengan bentuk yang aerodinamis berdasarkan rancangan ROV pada Gambar 1.

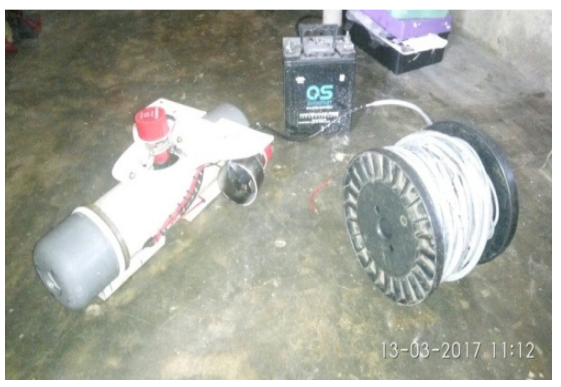

Gambar 4. Konstruki ROV

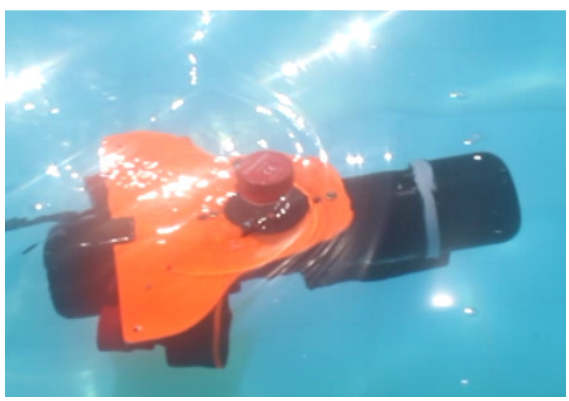

Gambar 5. Uji coba konstruksi ROV di air

Pada uji coba konstruksi ROV yang sudah dilakukan, maka dapat disimpulkan bahwa konstruksi ROV dapat mengapung dan tenggelam di air dengan stabil dan seimbang. Bentuk yang lebih aerodinamis menyebabkan ROV mampu bermanuver dengan cepat di dalam air.

\subsection{Daya ROV}

Daya ROV yang dihasilkan pada uji coba ROV dapat dilihat pada Tabel 1 di bawah ini :

Tabel 1. Daya ROV

\begin{tabular}{|c|c|c|c|c|c|}
\hline \multirow{3}{*}{ No. } & \multirow{3}{*}{ AKTIVITAS } & \multicolumn{4}{|c|}{ DAYA MOTOR ( W ) } \\
\hline & & \multicolumn{4}{|c|}{ KEDALAMAN } \\
\hline & & $\begin{array}{c}0 \\
\text { MTR }\end{array}$ & $\begin{array}{c}2 \\
\text { MTR }\end{array}$ & 3 MTR & $\begin{array}{l}\text { RATA- } \\
\text { RATA }\end{array}$ \\
\hline 1 & Maju & 83.64 & 93.48 & 97.60 & 91.57 \\
\hline 2 & Serong Kanan & 44.28 & 50.43 & 58.56 & 51.09 \\
\hline 3 & Belok Kanan & 84.18 & 85.40 & 85.20 & 84.93 \\
\hline 4 & $\begin{array}{l}\text { Serong Belakang } \\
\text { Kanan }\end{array}$ & 71.34 & 72.57 & 73.20 & 72.37 \\
\hline 5 & Mundur & 82.80 & 82.80 & 84.49 & 83.36 \\
\hline 6 & $\begin{array}{l}\text { Serong Belakang } \\
\text { Kiri }\end{array}$ & 82.41 & 86.10 & 90.28 & 86.26 \\
\hline 7 & Belok Kiri & 92.72 & 96.38 & 100.04 & 96.38 \\
\hline \multirow[t]{2}{*}{8} & Serong Kiri & 67.65 & 66.42 & 73.80 & 69.29 \\
\hline & \multicolumn{4}{|c|}{ Rata-rata Daya Motor $(\mathrm{W})=$} & 79.41 \\
\hline
\end{tabular}


Dari Tabel 1 di atas, maka dapat digambarkan grafik daya ROV yang dihasilkan pada beberapa aktivitas tersebut. Adapun gambar grafiknya adalah sebagai berikut :

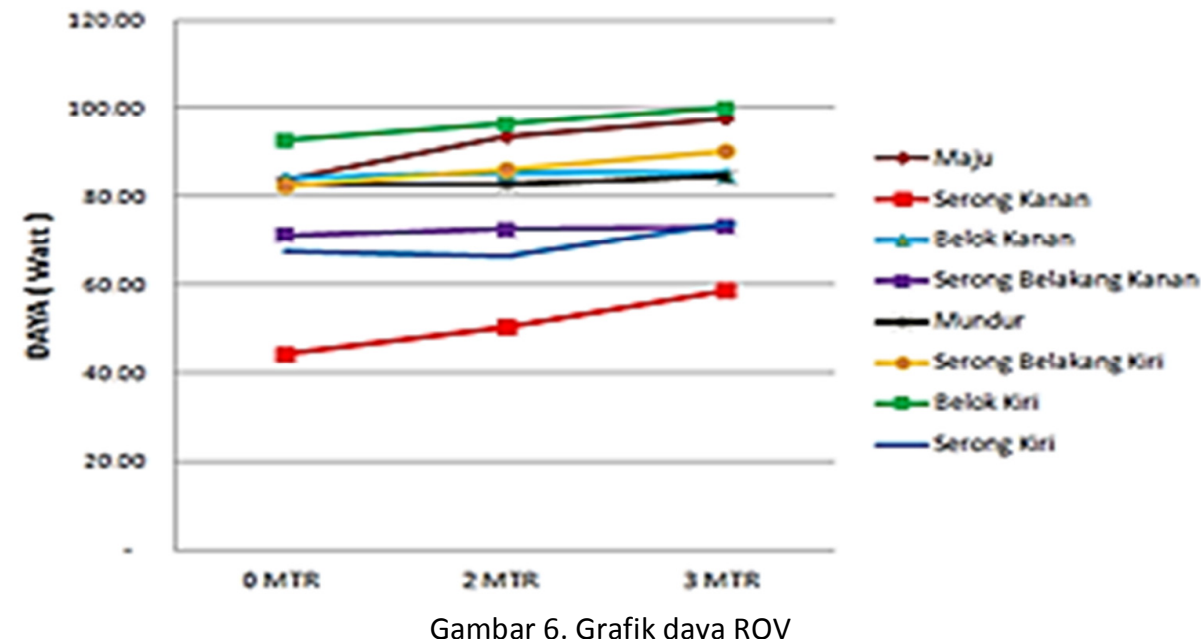

Dari grafik pada Gambar 6, dapat terlihat bahwa keadaan daya tertinggi berada pada saat aktivitas ROV berbelok ke kiri. Hal ini disebabkan karakteristik bilge pump yang modifikasi sebagai thruster memiliki sifat konsumsi daya yang berbeda pada saat polaritas diubah. Begitu juga pada saat aktivitas ROV berbelok ke kanan. Trend penggunaan daya di kedalaman yang lebih dalam menunjukan peningkatan konsumsi daya. Hal ini disebabkan oleh semakin besarnya tekanan di dalam air sehingga beban motor yang dihasilkan akan semakin besar.

Dari hasil uji coba pada Tabel 1, juga dapat terlihat bahwa rata-rata daya yang dihasilkan pada saat motor beroperasi di bawah air adalah 79.41 Watt dan tegangan motor yang digunakan cenderung konstan pada nilai $12.3 \mathrm{~V}$. Arus yang dihasilkan pada saat motor beroperasi di bawah air lebih besar daripada arus pada saat motor beroperasi di udara. Hal ini dikarenakan, motor memiliki beban yang lebih besar saat beroperasi di bawah air dibandingkan pada saat di udara.

Dari Tabel 1 di atas, maka daya yang dihasilkan pada saat ROV beroperasi di kedalaman $0 \sim 3$ meter adalah sebagai berikut [4][5]:

$\mathrm{P}=\mathrm{V} \times \mathrm{I}$

$=12.208 \mathrm{~V} \times 6.508 \mathrm{~A}$

$=79.455 \mathrm{Watt} \approx 79.4 \mathrm{Watt}$.

Kapasitas baterai $(C)$ yang digunakan pada uji coba untuk mengoperasikan ROV adalah sebesar $32 \mathrm{AH}$ yang artinya baterai mampu men-supply arus konstan sebesar $32 \mathrm{~A}$ dalam waktu satu jam, maka lama waktu robot beroperasi ( $\mathrm{t}$ ) jika konsumsi arus saat beroperasi (I) sebesar $6.508 \mathrm{~A}$ adalah sebagai berikut :

$t=\frac{C}{I}$

$=\frac{32 \mathrm{AH}}{6.508 \mathrm{~A}}=4.917 \mathrm{jam}$.

\subsection{Kecepatan ROV}

Kecepatan ROV yang dihasilkan pada uji coba ROV dapat dilihat pada tabel di bawah ini : 
Tabel 2. Kecepatan ROV

\begin{tabular}{cccccc}
\hline & & \multicolumn{4}{c}{ KECEPATAN } \\
\cline { 3 - 6 } NO. & & \multicolumn{4}{c}{ KEDALAMAN } \\
\cline { 3 - 6 } & \multirow{2}{*}{ AKTIVITAS } & $\mathbf{0}$ MTR & $\mathbf{2}$ & $\mathbf{3}$ & RATA- \\
& & & MTR & MTR & RATA \\
\hline 1 & Maju & 0.20 & 0.17 & 0.14 & 0.17 \\
2 & Mundur & 0.10 & 0.08 & 0.08 & 0.09 \\
\hline \multicolumn{3}{c}{ Rata-rata kecepatan $(\mathrm{m} / \mathrm{s})=$} \\
\hline
\end{tabular}

Dari Tabel 2 di atas, maka dapat digambarkan grafik kecepatan ROV yang dihasilkan pada beberapa aktivitas tersebut. Adapun gambar grafiknya adalah sebagai berikut :

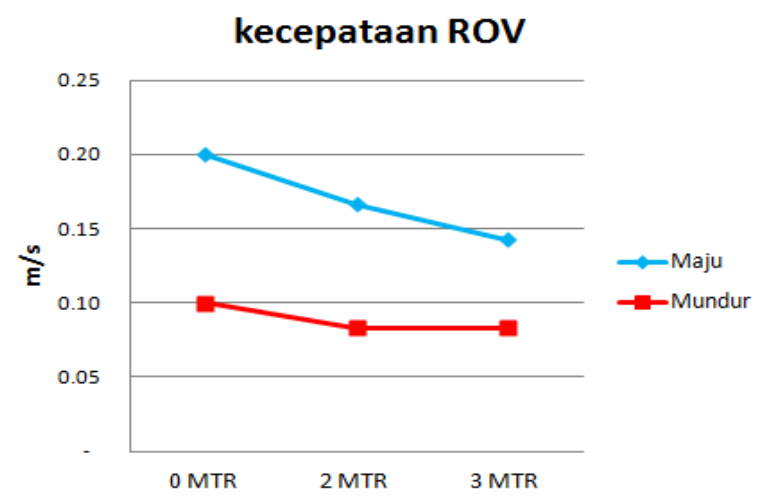

Gambar 7. Grafik kecepatan ROV

Dari grafik diatas dapat terlihat bahwa trend kecepatan ROV menurun linear terhadap peningkatan kedalaman. Olah gerak dari ROV akan semakin lambat seiring bertambah dalamnya pergerakan ROV dikarenakan semakin bsarnya tekanan di bawah air.

\section{SIMPULAN}

Setelah melakukan tahap perancangan dan pembuatan sistem yang kemudian dilanjutkan dengan tahap pengujian maka dapat diambil kesimpulan sebagai berikut:

1. Konstruksi ROV yang dibuat menggunakan pipa PVC tipe D dengan ukuran $\varnothing 4$ " sebagai rangka utama dan tempat rangkaian elektronika secara perhitungan mampu menahan tekanan hingga maksimal di kedalaman 30 meter, dengan actuator dan controller sebagai berikut :

Arduino Uno R3

Modified Bilge Pump

Joystick analog and Button interface

Relay driver

2. ROV dapat bergerak maju dan bermanuver di bawah air. Kecepatan rata-rata pergerakan ROV pada saat maju di kedalaman 3 meter adalah $0.171 \mathrm{~m} / \mathrm{s}$. 
3. Kecepatan rata-rata pergerakan ROV yang dibuats pada saat naik dari kedalaman 3 adalah 0.09 $\mathrm{m} / \mathrm{s}$. Sedangkan kecepatan rata-rata pergerakan ROV pada saat turun ke kedalaman 3 meter adalah $0.17 \mathrm{~m} / \mathrm{s}$.

\section{DAFTAR PUSTAKA}

[1]. R. Petrus, Menengok Masa Depan Dunia Robotika Indonesia, diakses pada 15 Desember 2016 Available : http://www.voaindonesia.com/a/menengok-masa-depan-dunia-robotikaindonesia/3376735.html.

[2] D. Daniel, Menjelajah Bawah Laut Dengan Mini ROV, diakses tanggal 23 Februari 2017, Available : http://www.p3tkp.litbang.kkp.go.id/index.php/litbang/inovasi-dan-hasil-penelitian/63-menjelajahbawah-laut-dengan-mini-rov.

[3] E. Novina, Cara Kerja ROV, Alat Pencari Air Asia QZ8501, diakses tanggal 22 Februari 2017, Available : http://nationalgeographic.co.id/berita/2015/01/cara-kerja-rov-alat-pencari-airasiaqz8501.

[4] P.A. Tipler, Alih bahasa : Lea Prasetio dan Rahmad W. Adi, Fisika untuk Sains dan Teknik. Edisi Ketiga : Cetakan 1 . Jakarta : Erlangga. Hal : 383-398, 1998.

[5] Fisika Zone. Collage Loan Consolidation. Hukum Archimedes, diakses tanggal 12 Maret 2017, Available : http://fisikazone.com/hukum-archimedes/.

[6] Young, H.D. dan R.A. Freedman, Sears and Zemansky Fisika Univertas Edisi 10 Jilid 2, Jakarta: Erlangga, 2003.

[7] Gitakarma, M.S., Ariawan, K.U., Wigraha, N.A, Alat Bantu Survey Bawah Air menggunakan Amoba, Robot Berbasis ROV. 3 (2) : 392-409, 2014. 